\title{
Gonadal and Sexual Dysfunction in Childhood Cancer Survivors
}

Ju Young Yoon, MD',
Hyeon Jin Park, MD, PhD'
Hee Young Ju, MD'
Jong Hyung Yoon, MD1,
Jin Soo Chung, MD, PhD'
Sang Hyun Hwang, MD, PhD'
Dong Ock Lee, MD
Hye Young Shim, PhD
Byung-Kiu Park, MD, PhD'

${ }^{1}$ Center for Pediatric Cancer, National Cancer Center, Goyang, ${ }^{2}$ Center for Prostate Cancer, National Cancer Center, Goyang, ${ }^{3}$ Department of Laboratory Medicine, National Cancer Center, Goyang, ${ }^{4}$ Center for Uterine Cancer,

National Cancer Center, Goyang, ${ }^{5}$ Division of Cancer Management Policy, National Cancer Center, Goyang, Korea

Correspondence: Hyeon Jin Park, MD, PhD Center for Pediatric Cancer, National Cancer Center, 323 Ilsan-ro, Ilsandong-gu, Goyang 10408, Korea Tel: 82-31-920-1654

Fax: 82-31-920-1244

E-mail: hjpark@ncc.re.kr

Received May 10, 2016

Accepted January 11, 2017

Published Online January 25, 2017

aPresent address: Department of Pediatrics, Gyeongsang National University Changwon Hospital, Changwon, Korea

'Present address: Department of Pediatrics, Hallym University College of Medicine,

Chuncheon, Korea

'Present address: Department of Laboratory Medicine, Asan Medical Center, University of Ulsan College of Medicine, Seoul, Korea

\section{Purpose}

Few studies have addressed gonadal and sexual dysfunctions in childhood cancer survivors. We evaluated the prevalence rates and risk factors for gonadal failure among adolescent/ young adult childhood cancer survivors and their sexual function.

\section{Materials and Methods}

Subjects were childhood cancer survivors aged 15-29 years who had completed therapy more than 2 years ago. Demographic and medical characteristics were obtained from the patients' medical records. In addition, hormonal evaluation and semen analysis were performed and sexual function was evaluated via questionnaire.

\section{Results}

The study included 105 survivors (57 males, 48 females), of which 61 were adults (age > 19 years) and 44 were adolescents. In both males and females, the proportion of survivors with low sex hormone levels did not differ among age groups or follow-up period. Thirteen female subjects (27.1\%) needed sex hormone replacement, while five males subjects (8.8\%) were suspected of having hypogonadism, but none were receiving sex hormone replacement. Of 27 semen samples, 14 showed azospermia or oligospermia. The proportion of normospermia was lower in the high cyclophosphamide equivalent dose (CED) group (CED $\geq 8,000 \mathrm{mg} / \mathrm{m}^{2}$ ) than the low CED group ( $27.3 \%$ vs. $62.5 \%, \mathrm{p}=0.047$ ). Among adults, none were married and only 10 men (35.7\%) and eight women (34.3\%) were in a romantic relationship. Though a significant proportion (12.0\% of males and $5.3 \%$ of females) of adolescent survivors had experienced sexual activity, 13.6\% had not experienced sex education.

\section{Conclusion}

The childhood cancer survivors in this study showed a high prevalence of gonadal/sexual dysfunction; accordingly, proper strategies are needed to manage these complications.

\section{Key words}

Gonads, Sexual dysfunction, Survivors, Child, Neoplasms 


\section{Introduction}

According to the 2011 Korea National Cancer Incidence Database, the 5-year event-free survival rate of Korean children aged 0 to 14 years with cancer between 2007 and 2011 was $78.2 \%$ [1]. As the survival rates for childhood cancer increase, the number of survivors with long-term complications is also increasing.

One of the important late complications of cancer survivors is gonadal dysfunction. In adult survivors of childhood lymphoma, gonadal failure was reported in $11 \%$ of males and $44 \%$ of females [2]. In female childhood cancer survivors, the risk of premature menopause was 13.2 times higher than for their siblings ( $8 \%$ vs. $0.8 \%$ ) [3]. Spermatogenesis also can be impaired in childhood cancer survivors. Specifically, applying radiation to the testes or treatment with alkylating agents are known risk factors of impaired spermatogenesis. In a recent study, azospermia was reported in $25 \%$ of childhood cancer survivors who received an alkylating agent [4]. Sexual dysfunction is also an important complication that can affect quality of life, but its effects have rarely been evaluated in childhood cancer survivors. Moreover, few studies have investigated both gonadal and sexual dysfunction, even though these complications tend to occur concurrently and may influence each other. Therefore, gonadal and sexual function of childhood cancer survivors were evaluated in this study.

\section{Materials and Methods}

\section{Subjects}

This study includes patients who visited an outpatient clinic of the Center for Pediatric Cancer of the National Cancer Center in Korea. Patients were less than 20 years old when diagnosed with cancer and were between 15 and 30 years old during the period when this study was conducted. More than 2 years had passed since the completion of therapy, and there was no evidence of recurrence. This study recruited data describing childhood cancer survivors who visited the hospital between July 2013 and February 2016. The Institutional Review Board of the National Cancer Center approved the study protocol (NCCNCS13741).

\section{Procedure}

Demographic and medical characteristics were obtained from the patient medical records. Radiation records were also reviewed to gather data about radiation area and dose. Information regarding chemotherapy agents used for each patient was obtained from chemotherapy records. Cyclophosphamide equivalent dose (CED) was calculated according to the following formula: $\mathrm{CED}\left(\mathrm{mg} / \mathrm{m}^{2}\right)=1.0$ (cumulative cyclophosphamide dose $\left[\mathrm{mg} / \mathrm{m}^{2}\right]$ ) +0.244 (cumulative ifosfamide dose $\left[\mathrm{mg} / \mathrm{m}^{2}\right]$ ) +0.857 (cumulative procarbazine dose $\left.\left[\mathrm{mg} / \mathrm{m}^{2}\right]\right)+14.286$ (cumulative chlorambucil dose $\left[\mathrm{mg} / \mathrm{m}^{2}\right]$ ) +15.0 (cumulative carmustine dose $\left[\mathrm{mg} / \mathrm{m}^{2}\right]$ ) +16.0 (cumulative lomustine dose $\left[\mathrm{mg} / \mathrm{m}^{2}\right]$ ) +40 (cumulative melphalan dose $\left.\left[\mathrm{mg} / \mathrm{m}^{2}\right]\right)+50$ (cumulative thiotepa dose $\left.\left[\mathrm{mg} / \mathrm{m}^{2}\right]\right)+100$ (cumulative chlormethine dose $\left[\mathrm{mg} / \mathrm{m}^{2}\right]$ ) +8.823 (cumulative busulfan dose $\left[\mathrm{mg} / \mathrm{m}^{2}\right]$ ), as suggested in a previous study [5].

Hormonal evaluation included follicle-stimulating hormone (FSH), luteinizing hormone (LH), and testosterone or estradiol. In females, the anti-mullerian hormone (AMH) level was also evaluated. To accomplish this, we used electrochemiluminescent immunoassay for FSH/LH, chemiluminescent immunoassay for estradiol, radioimmunoassay for testosterone, and enzyme-linked immunosorbent assay for AMH level.

Male participants collected their semen via masturbation, and samples were processed within 30 minutes of collection. As part of the analysis, semen amount and sperm concentration was checked and the morphology and motility of sperm were evaluated. Azospermia was defined as no sperm observed, and oligospermia was defined as a sperm concentration of less than $15 \times 10^{6} / \mathrm{mL}$ based on the World Health Organization reference values [6].

\section{Questionnaire}

Questionnaires were presented to participants when they visited our clinic, and were returned either immediately at the clinic or later via mail. Four types of questionnaires were administered, for adolescents younger than 19 years old, adult men, adult women, and parents. Each questionnaire contained questions about quality of life and health behavior. In addition, questions about sexual function were included in questionnaires for adult men and women. Questions regarding sexual function included questions from previously validated questionnaires about male erectile function (Korean version of the International Index of Erectile Function [IIEF-5]) [7,8] and about female sexual function (Koreanversion of the Female Sexual Function Index [FSFI]) $[9,10]$. Both of these questionnaires are supplied as supplementary tables (S1 and S2 Tables). For adolescents, questions from the 8th Korean Youth Risk Behavior Web-based Survey were used [11]. Survivors were also asked if they had received official sex education from a school teacher or other provider. 


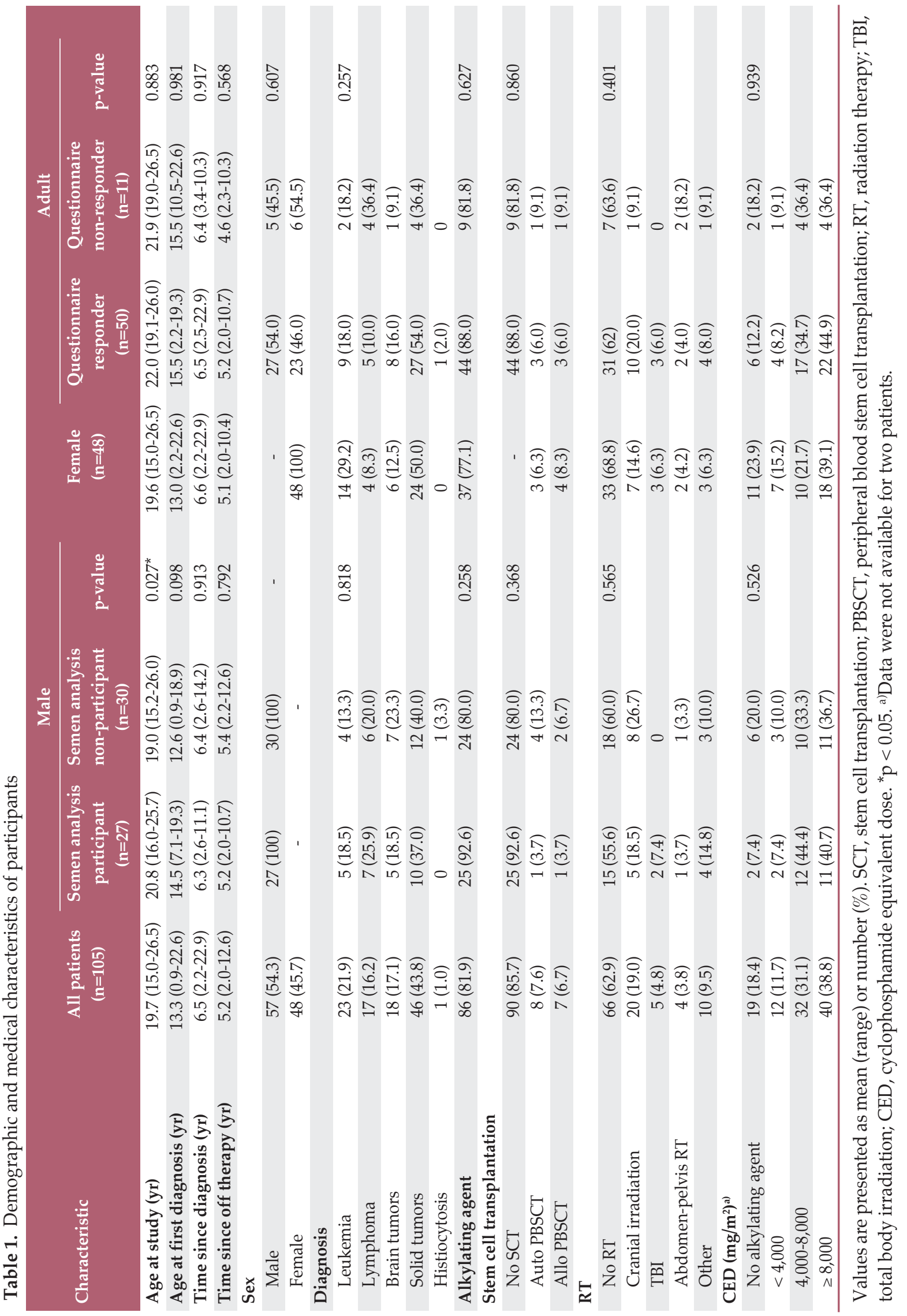


Table 2. Gonadal function of females $(n=48)$

\begin{tabular}{|c|c|c|c|c|c|c|c|}
\hline \multirow[b]{2}{*}{ Gonadal function } & \multirow{2}{*}{$\begin{array}{l}\text { All females } \\
\qquad(\mathrm{n}=48)\end{array}$} & \multicolumn{3}{|c|}{ Age at diagnosis (yr) } & \multicolumn{3}{|c|}{ Time since off therapy (yr) } \\
\hline & & $\begin{array}{l}<13.1 \\
(n=24)\end{array}$ & $\begin{array}{l}\geq 13.1 \\
(n=24)\end{array}$ & p-value & $\begin{array}{c}<5 \\
(n=30)\end{array}$ & $\begin{array}{c}\geq 5 \\
(n=18)\end{array}$ & p-value \\
\hline Gonadotropin deficiencya) & 1 & 1 & 0 & - & 0 & 1 & - \\
\hline $\mathrm{AMH}<1.19 \mathrm{ng} / \mathrm{mL}$ & $24(51.1)$ & $11(47.8)$ & $13(54.2)$ & 0.773 & $16(53.3)$ & $8(44.4)$ & 0.679 \\
\hline Sex hormone replacement & $13(27.1)$ & $6(25.0)$ & $7(29.2)$ & 0.745 & $8(26.7)$ & $5(27.8)$ & 1.000 \\
\hline
\end{tabular}

Values are presented as number (\%). $\mathrm{AMH}$, anti-mullerian hormone. ${ }^{\mathrm{a}}$ Evaluated in only one patient.

Table 3. Gonadal function of males

\begin{tabular}{|c|c|c|c|c|c|c|c|}
\hline \multirow[b]{2}{*}{ Gonadal function } & \multirow{2}{*}{$\begin{array}{l}\text { All males } \\
\qquad(n=57)\end{array}$} & \multicolumn{3}{|c|}{ Age at diagnosis (yr) } & \multicolumn{3}{|c|}{ Time since off therapy (yr) } \\
\hline & & $\begin{array}{l}<14.6 \\
(n=27)\end{array}$ & $\begin{array}{l}\geq 14.6 \\
(n=30)\end{array}$ & p-value & $\begin{array}{c}<5 \\
(n=31)\end{array}$ & $\begin{array}{c}\geq 5 \\
(n=26)\end{array}$ & p-value \\
\hline Testosterone $<325 \mathrm{ng} / \mathrm{dL}$ & $5(8.8)$ & $2(7.4)$ & $3(10.0)$ & 1.000 & $3(9.7)$ & $2(7.7)$ & 1.000 \\
\hline Testis volume $<15 \mathrm{~cm}^{3, a)}$ & $5(8.8)$ & $1(3.7)$ & $4(13.3)$ & 0.588 & $5(16.1)$ & 0 & $0.026^{*}$ \\
\hline Sex hormone replacement & 0 & 0 & 0 & - & 0 & 0 & - \\
\hline
\end{tabular}

Values are presented as number $(\%) .{ }^{*} \mathrm{p}<0.05$. ${ }^{\mathrm{a}}$ Evaluated in 16 patients.

\section{Statistical analysis}

Demographic and treatment characteristics of participants were assessed using descriptive statistics. For comparison of continuous variables among groups, an independent t test was used. A chi-squared test and Fisher exact test were used for comparison of categorical variables. SPSS ver. 20 (IBM Corp., Armonk, NY), was used for all quantitative analyses. p-values less than 0.05 were considered significant.

\section{Results}

\section{Patient characteristics}

This study included survivors who visited the hospital between July 2013 and February $2016(n=105)$. Of the 105 survivors, 92 responded to the questionnaire (response rate, $78.6 \%$ ). Among 61 adults, 50 replied to the questionnaire. Overall, 27 males agreed to the semen analysis.

Demographic and treatment characteristics of participants are presented in Table 1. CED was calculated for all patients who received an alkylating agent, except for two female patients who received chemotherapy at an outside hospital for whom information about the doses of alkylating agents could not be obtained. Semen analysis participants were older than non-participants $(p=0.027)$, and there were no other differences between semen analysis participants and non-participants or between questionnaire responders and non-responders (Table 1).

\section{Gonadal function of females}

Among 48 females, $13(27.1 \%)$ required sex hormone replacement; 10 were already receiving sex hormone therapy before our study, and three had newly started sex hormone replacement because of amenorrhoea/oligomenorrhoea due to low estradiol levels. One woman showed gonadotropin deficiency in the gonadotropin-releasing hormone ( $\mathrm{GnRH})$ stimulation test. The AMH level was below $1.19 \mathrm{ng} / \mathrm{mL}$ (fifth percentile cut-off value for Korean women aged 20-31) in 24 women $(51.1 \%)$. Among women receiving hormone replacement, $11(84.6 \%)$ had an AMH level less than $1.19 \mathrm{ng} / \mathrm{mL}$. Among seven females who received stem cell transplantation, six $(85.7 \%)$ received sex hormone replacement (data not shown). We divided female survivors into two groups according to median age (13.1 years), and there was no difference in gonadal function between groups. There was also no difference when the results were divided into follow-up periods of 5 years (Table 2). 
Table 4. Semen profile

\begin{tabular}{lccc} 
Semen & $\begin{array}{c}\text { All semen analysis } \\
\text { participants }(\mathbf{n = 2 7 )}\end{array}$ & $\begin{array}{c}\text { CED } \geq 8,000 ~ \mathbf{~ m g} / \mathbf{m}^{2} \\
(\mathbf{n}=\mathbf{1 1})\end{array}$ & $\begin{array}{c}\text { CED }<8, \mathbf{0 0 0} \mathbf{~ m g} / \mathbf{m}^{2} \\
(\mathbf{n}=\mathbf{1 6})^{\mathbf{a})}\end{array}$ \\
Normospermia & $13(48.1)$ & $3(27.3)$ & $10(62.5)$ \\
Oligospermia & $3(11.1)$ & $1(9.1)$ & $2(12.5)$ \\
Azospermia & $11(40.7)$ & $7(63.6)$ & $4(25)$ \\
\hline
\end{tabular}

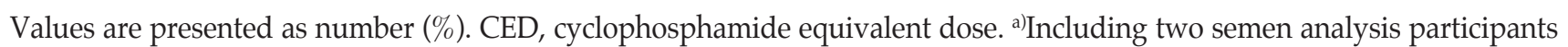
who had not received alkylating agent.

Table 5. Sexual function of adult survivors ( $\geq 19$ years)

\begin{tabular}{lcc} 
Variable & Male $(\mathbf{n}=\mathbf{2 8})$ & Female $(\mathbf{n}=\mathbf{2 3})$ \\
\hline Boy/Girlfriend & $10(35.7)$ & $8(34.8)$ \\
Married & 0 & 0 \\
$\begin{array}{l}\text { Sexual activity within } \\
\text { the past month }\end{array}$ & & \\
0-1 per week & & $8(34.8)$ \\
2-3 per week & $11(39.3)$ & $5(21.7)$ \\
4-7 per week & $7(25.0)$ & 0 \\
\hline No reply & $1(3.6)$ & $10(43.5)$ \\
\hline Erectile dysfunction ${ }^{\text {b) }}$ & $9(32.1)$ & \\
\hline
\end{tabular}

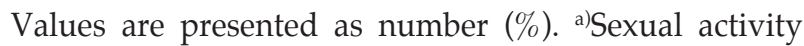
included not only sexual intercourse, but also kissing/ caressing, b)Erectile dysfunction was evaluated in 10 males who had a girlfriend.

\section{Gonadal function of males}

Among the 57 male participants, five $(8.8 \%)$ had testosterone level below $325 \mathrm{ng} / \mathrm{dL}$, suggestive of male hypogonadism (Table 3). Additionally, five males had testis volumes of less than $15 \mathrm{~cm}^{3}$. All five survivors with small testis volumes had normal testosterone levels, but four of them had azoospermia (data not shown). None of the male participants was receiving sex hormones. When divided into two groups according to median age (14.6 years), no difference in gonadal function was observed. However, when divided into follow-up durations of 5 years, all five males with testis volumes of less than $15 \mathrm{~cm}^{3}$ were in the group with a followup period of less than 5 years (Table 3 ).

Semen analysis was performed for 27 males, and azospermia and oligospermia were observed in 11 (37.5\%) and three $(12.5 \%)$ of the semen analysis participants, respectively. We further divided semen analysis participants into two groups according to CED (high CED [CED $\left.\geq 8,000 \mathrm{mg} / \mathrm{m}^{2}\right] \mathrm{vs}$. low
Table 6. Sexual function of adolescent survivors (15-18 years)

\begin{tabular}{lrc} 
Variable & Male $(\mathbf{n}=\mathbf{2 5})$ & Female $(\mathbf{n}=\mathbf{1 9})$ \\
$\begin{array}{l}\text { Experience of } \\
\text { sexual activity }\end{array}$ & $3(12.0)^{\mathrm{b})}$ & $1(5.3)^{\mathrm{b})}$ \\
$\begin{array}{c}\text { Experience of } \\
\text { sex education }\end{array}$ & $21(84.0)$ & $17(89.5)$ \\
\hline
\end{tabular}

Values are presented as number (\%). ${ }^{a}$ Sexual activity included not only sexual intercourse, but also kissing/ caressing, b) Reference value for healthy high school students: $9.8 \%$ for males and 3.5\% for females (from the 11th Korean Youth Risk Behavior Web-based Survey in 2015) [12].

CED [CED $\left.\left.<8,000 \mathrm{mg} / \mathrm{m}^{2}\right]\right)$. The proportion of normospermia was lower in the high CED group than in the low CED group (27.3\% vs. $62.5 \%, \mathrm{p}=0.047)$ (Table 4$)$. Both males who had never used an alkylating agent showed normospermia.

\section{Sexual function of survivors}

Sexual function of adult survivors is listed in Table 5. Among 50 adults, 27 males and 23 females replied to questionnaire. None of the adult survivors were married, although ten males and eight females were in a relationship. Among 10 males who had a girlfriend, two (20\%) had severe erectile dysfunction (IIEF score $\leq 7$ ) (Table 5). Questions regarding the FSFI are supplied in S2 Table.

Sexual function of adolescent survivors was evaluated in 25 males and 19 females. While adolescent survivors had similar experiences with sexual activity as normal high school students, six $(13.6 \%)$ had not received any kind of sex education (Table 6). 


\section{Discussion}

In this study, the gonadal and sexual function of adolescent and young adult childhood cancer survivors was evaluated. Gonadal failure is classified into central hypogonadism (due to gonadotropin deficiency) and primary hypogonadism. Childhood cancer survivors are at increased risk of both central and primary hypogonadism because of radiation and chemotherapy. It is not possible to clearly distinguish central from primary hypogonadism because a GnRH stimulation test was only performed for one female in our study. However, it is believed that many patients have combined central and primary gonadal failure since 17 (16.2\%) had received both brain radiation and gonadotoxic chemotherapy (data not shown).

Among female participants, $27.1 \%$ were taking sex hormones due to ovarian failure. Among female participants of the Childhood Cancer Survivor Study, acute ovarian failure was reported in 215 of 3,390 females (6.3\%) [13], and 125 of $2,819(4.5 \%)$ had premature ovarian failure [14]. Our higher prevalence of ovarian failure is partially explained by the relatively high prevalence of survivors who received alkylating agents. In previous studies, the proportion of participants who had received alkylating agents was $49.7 \%$ and $48.4 \%$, respectively $[13,14]$, lower than that in our study.

$\mathrm{AMH}$ is used as a marker to evaluate ovarian function because it is not affected by menstrual cycle or exogenous estrogen. Although AMH is not yet recommended as a routine screening tool for gonadal function in childhood cancer survivors, it is believed to be a useful marker to evaluate ovarian reserve in female childhood cancer survivors, especially in those at risk for ovarian failure. Lunsford et al. [15] suggested that AMH could be the optimal screening method for assessing ovarian reserve in childhood cancer survivors.

AMH levels vary according to age, and a cut-off value has not been established. Our study used reference values for normal Korean females reported in 2011 [16]. Based on this reference, the AMH level was below the third percentile in $24(51.1 \%)$ women. This cut-off value seems reasonable because $45.8 \%$ of patients ( 11 of 24 ) with an AMH below this level required hormone replacement due to amenorrhoea.

No male participants had received hormone replacement therapy. The decision to undergo sex hormone replacement may have been more difficult for men than women because there is no clinical indicator of gonadal function, such as menstruation. Testis volume can be a useful marker for gonadal function in males and is known to be related to semen profiles in normal and infertile men [17-19]. In our study, all males with a testis volume less than $15 \mathrm{~cm}^{3}$ had a follow-up period of less than 5 years, suggesting a relationship between follow-up period and testis volume. However, the number of patients was too small to evaluate the relationship between follow-up period and testis volume; therefore, a longitudinal study involving a larger number of survivors is required. In addition to symptoms directly associated with androgen deficiency, gonadal failure in males can result in an increased risk of osteoporosis and metabolic disorders $[20,21]$. Therefore, we should pay special attention to the management of male hypogonadism. It is recommended that adolescent or young adult childhood cancer survivors treated with gonadotoxic therapy be monitored annually for symptoms of androgen deficiency, including decreased libido, decreased erections, and reduced testicular volume [22].

Risk of gonadal failure is also associated with age at diagnosis or pubertal stage at diagnosis. In females, exposure of the ovaries to chemotherapy or radiotherapy at older age was a significant risk factor for ovarian failure in a previous study [3]. In the present study, the prevalence of ovarian failure did not differ according to age group. However, this result can be influenced by a shorter follow up period in older age groups ( 6.2 years vs. 3.9 years, $\mathrm{p}=0.002$ ), and longterm follow-up data is required to evaluate the relationship clearly. In males, radiosensitivity is higher in prepubertal boys than adult men; therefore, the testicular irradiation dose inducing Leydig cell dysfunction is lower in prepubertal subjects than males after puberty [23]. As a result, we assumed that more survivors who received radiation or gonadotoxic chemotherapy in the prepubertal stage had gonadal failure than those who received it at the pubertal or post-pubertal stage. The pubertal stage at diagnosis was not recorded in all patients, so we instead used the median age to divide survivors into two groups, between which no difference in prevalence of gonadal failure was observed. However, additional studies accurately examining pubertal status and investigating its relationship with gonadal function are required.

Fertility after male childhood cancer is most often evaluated based on sperm count determined by semen analysis. In the present study, half of the patients who underwent semen analysis showed azospermia or oligospermia. In a previous report that described the semen profiles of 214 adult childhood cancer survivors, azospermia or oligospermia was reported in $25 \%$ and $48 \%$ of study participants, respectively, which is similar to our findings [4]. In male childhood cancer survivors, chemotherapeutic agents, especially alkylating agents, surgery, or radiation to the testes, can impair spermatogenesis. Green et al. [5] proposed CED as an estimation of alkylating agent exposure. In another study conducted by Green et al. [4], CED was significantly associated with an increased risk of azospermia and oligospermia. In the present study, consistent with previous findings, azo/oligospermia was more common in the high CED group than the low 
CED group.

Sexual dysfunction in childhood cancer survivors can result from impairment of any process associated with sexual intercourse such as desire, erection, ejaculation, or orgasm. Surgery or irradiation (especially of the pelvis), hormonal insufficiencies, and medical comorbidities are possible etiologies of sexual dysfunction in childhood cancer survivors [24]. In a previous study of 282 young childhood cancer survivors, $52 \%$ of females and $32 \%$ of males had a problem in one or more areas of sexual function [25].

Proper sex education is required for childhood cancer survivors and their partners' health and quality of life. In our study, more than $10 \%$ of adolescent survivors had not received official sex education, indicating that strategies to provide such education are needed.

The most important aspect of our study is that we evaluated gonadal function, sexual function, and romantic relationships altogether, whereas most previous studies have investigated only of these areas. Although one previous study examined both gonadal and sexual function in childhood cancer survivors, it included only male survivors [26].

It should be noted that our study was limited in that the participants were uniformly young, with many in their early 20s. Additionally, none of the participants were married. Taken together, these factors may have led to underestimation of sexual function. Another limitation is that the followup duration after treatment was short and no longitudinal follow-up was conducted. A previous study reported that $8 \%$ of 2,819 female childhood cancer survivors experienced premature menopause before the age of 40 [4]. In another study that followed hematopoietic stem cell recipients (median follow-up of 7.2 years), the cumulative incidence of ovarian failure was 56\% [27]. Longitudinal follow-up studies should be continued considering the rapid changes in treatment regimen favoring gonad protection.

Moreover, evaluation of sexual function was limited to simple questions about sexual activity, satisfaction and erectile dysfunction. Longitudinal long-term follow-up studies and more detailed investigation of other aspects of sexual function and consideration of the risk factors of sexual dysfunction should be investigated in future studies.

In conclusion, the childhood cancer survivors in this study showed a high prevalence of gonadal/sexual dysfunction. Accordingly, proper strategies for managing these complications, including appropriate sex education, should be established to improve their quality of life.

\section{Electronic Supplementary Material}

Supplementary materials are available at Cancer Research and Treatment website (http:// www.e-crt.org).

\section{Conflicts of Interest}

Conflict of interest relevant to this article was not reported.

\section{Acknowledgments}

This work was supported by a Career Development Award from the National Cancer Center in Goyang, Korea (Grant number 13C0030-1). The study design, data collection and analysis, and writing and submission of the paper were not affected by the funding.

\section{References}

1. Park HJ, Moon EK, Yoon JY, Oh CM, Jung KW, Park BK, et al. Incidence and survival of childhood cancer in Korea. Cancer Res Treat. 2016;48:869-82.

2. Hamre H, Kiserud CE, Ruud E, Thorsby PM, Fossa SD. Gonadal function and parenthood 20 years after treatment for childhood lymphoma: a cross-sectional study. Pediatr Blood Cancer. 2012;59:271-7.

3. Green DM, Sklar CA, Boice JD Jr, Mulvihill JJ, Whitton JA, Stovall $\mathrm{M}$, et al. Ovarian failure and reproductive outcomes after childhood cancer treatment: results from the Childhood Cancer Survivor Study. J Clin Oncol. 2009;27:2374-81.

4. Green DM, Liu W, Kutteh WH, Ke RW, Shelton KC, Sklar CA, et al. Cumulative alkylating agent exposure and semen parameters in adult survivors of childhood cancer: a report from the St Jude Lifetime Cohort Study. Lancet Oncol. 2014;15:1215-23.

5. Green DM, Nolan VG, Goodman PJ, Whitton JA, Srivastava
D, Leisenring WM, et al. The cyclophosphamide equivalent dose as an approach for quantifying alkylating agent exposure: a report from the Childhood Cancer Survivor Study. Pediatr Blood Cancer. 2014;61:53-67.

6. Cooper TG, Noonan E, von Eckardstein S, Auger J, Baker HW, Behre HM, et al. World Health Organization reference values for human semen characteristics. Hum Reprod Update. 2010; 16:231-45.

7. Ahn TY, Lee DS, Kang WC, Hong JH, Kim YS. Validation of an abridged Korean version of the International Index of ErectileFunction (IIEF-5) as a diagnostic tool for erectile dysfunction. Korean J Urol. 2001;42:535-40.

8. Rosen RC, Cappelleri JC, Smith MD, Lipsky J, Pena BM. Development and evaluation of an abridged, 5-item version of the International Index of Erectile Function (IIEF-5) as a diagnostic tool for erectile dysfunction. Int J Impot Res. 
1999;11:319-26.

9. Kim HY, So HS, Park KS, Jeong SJ, Lee JY, Ryu SB. Development of the Korean-version of Female Sexual Function Index (FSFI). Korean J Androl. 2002;20:50-6.

10. Rosen R, Brown C, Heiman J, Leiblum S, Meston C, Shabsigh $\mathrm{R}$, et al. The Female Sexual Function Index (FSFI): a multidimensional self-report instrument for the assessment of female sexual function. J Sex Marital Ther. 2000;26:191-208.

11. Ministry of Education, Science and Technology; Ministry of Health and Welfare; Korea Centers for Disease Control and Prevention. The eighth Korea Youth Risk Behavior Web-based Survey, 2012. Seoul: Korea Centers for Disease Control and Prevention; 2012.

12. Korea Centers for Disease Control and Prevention. The statistics of 2015 Korea Youth Health Risk Behavior Online Survey 2015 [Internet]. Cheongju: Centers for Disease Control and Prevention; 2015 [cited 2016 May 10]. Available from: http: //yhs.cdc.go.kr.

13. Chemaitilly W, Mertens AC, Mitby P, Whitton J, Stovall M, Yasui $Y$, et al. Acute ovarian failure in the childhood cancer survivor study. J Clin Endocrinol Metab. 2006;91:1723-8.

14. Sklar CA, Mertens AC, Mitby P, Whitton J, Stovall M, Kasper $\mathrm{C}$, et al. Premature menopause in survivors of childhood cancer: a report from the childhood cancer survivor study. J Natl Cancer Inst. 2006;98:890-6.

15. Lunsford AJ, Whelan K, McCormick K, McLaren JF. Antimullerian hormone as a measure of reproductive function in female childhood cancer survivors. Fertil Steril. 2014;101: 227-31.

16. Yoo JH, Kim HO, Cha SW, Park CW, Yang KM, Song IO, et al. Age specific serum anti-Mullerian hormone levels in 1,298 Korean women with regular menstruation. Clin Exp Reprod Med. 2011;38:93-7.

17. Sakamoto H, Yajima T, Nagata M, Okumura T, Suzuki K, Ogawa Y. Relationship between testicular size by ultrasonography and testicular function: measurement of testicular length, width, and depth in patients with infertility. Int J Urol. 2008;15:529-33.
18. Aribarg A, Kenkeerati W, Vorapaiboonsak V, Leepipatpaiboon S, Farley TM. Testicular volume, semen profile and serum hormone levels in fertile Thai males. Int J Androl. 1986;9:170-80.

19. Arai T, Kitahara S, Horiuchi S, Sumi S, Yoshida K. Relationship of testicular volume to semen profiles and serum hormone concentrations in infertile Japanese males. Int J Fertil Womens Med. 1998;43:40-7.

20. Greenfield DM, Walters SJ, Coleman RE, Hancock BW, Eastell $\mathrm{R}$, Davies HA, et al. Prevalence and consequences of androgen deficiency in young male cancer survivors in a controlled cross-sectional study. J Clin Endocrinol Metab. 2007;92: 3476-82.

21. Howell SJ, Radford JA, Adams JE, Shalet SM. The impact of mild Leydig cell dysfunction following cytotoxic chemotherapy on bone mineral density (BMD) and body composition. Clin Endocrinol (Oxf). 2000;52:609-16.

22. Romerius P, Stahl O, Moell C, Relander T, Cavallin-Stahl E, Wiebe $\mathrm{T}$, et al. Hypogonadism risk in men treated for childhood cancer. J Clin Endocrinol Metab. 2009;94:4180-6.

23. Shalet SM, Tsatsoulis A, Whitehead E, Read G. Vulnerability of the human Leydig cell to radiation damage is dependent upon age. J Endocrinol. 1989;120:161-5.

24. Kenney LB, Cohen LE, Shnorhavorian M, Metzger ML, Lockart B, Hijiya N, et al. Male reproductive health after childhood, adolescent, and young adult cancers: a report from the Children's Oncology Group. J Clin Oncol. 2012;30:3408-16.

25. Zebrack BJ, Foley S, Wittmann D, Leonard M. Sexual functioning in young adult survivors of childhood cancer. Psychooncology. 2010;19:814-22.

26. Ahn TY, Park JK, Lee SW, Hong JH, Park NC, Kim JJ, et al. Prevalence and risk factors for erectile dysfunction in Korean men: results of an epidemiological study. J Sex Med. 2007;4: 1269-76.

27. Bresters D, Emons JA, Nuri N, Ball LM, Kollen WJ, Hannema SE, et al. Ovarian insufficiency and pubertal development after hematopoietic stem cell transplantation in childhood. Pediatr Blood Cancer. 2014;61:2048-53. 